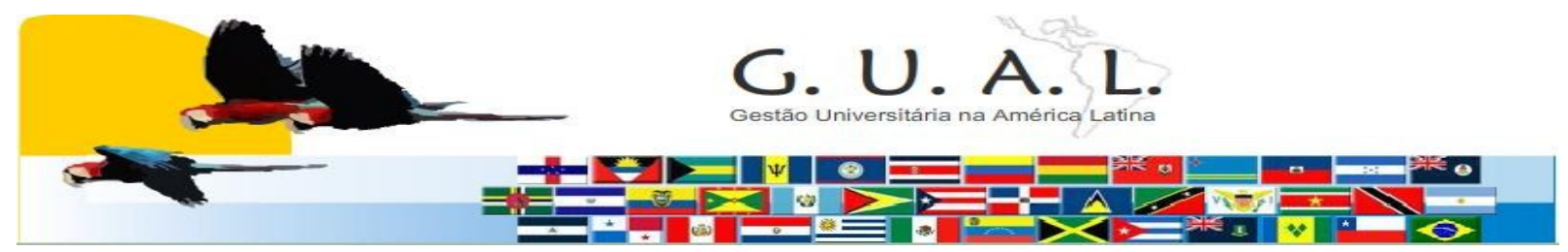

ISSN 1983-4535

\title{
ANÁLISE DAS PRESTAÇÕES DE CONTAS NA INTERNET DA UNIVERSIDADE DO ESTADO DE SANTA CATARINA
}

\section{PERFORMANCE REVIEW OF INTERNET ACCOUNTS OF STATE UNIVERSITY OF SANTA CATARINA}

Rafael Oliveira Bezerra, Graduando Universidade Federal de Santa Catarina - UFSC rafobez@gmail.com

Loreci João Borges, Doutor Universidade Federal de Santa Catarina - UFSC ljb@ljb.com.br

Sandra Mara Iesbik Valmorbida, Mestre Universidade Federal de Santa Catarina - UFSC smiesbik@gmail.com

Recebido em 17/dezembro/2011

Aprovado em 26/março/2012

Sistema de Avaliação: Double Blind Review

Esta obra está sob uma Licença Creative Commons Atribuição-Uso. 


\title{
RESUMO
}

A transparência dos atos e as prestações de contas dos gastos públicos são temas de grande relevância social e suas ausências são recorrentes nas discussões sobre as falhas da administração pública e se constituem como agentes da democracia, da eficiência e da mudança. O objetivo deste artigo é demonstrar as práticas de publicidade da UDESC na Internet e avaliá-las em relação à legislação. Esta pesquisa tem caráter descritivo com abordagem qualitativa por meio de pesquisa documental, a partir de dados secundários advindos do sítio da UDESC. Foram utilizados check-list para coleta de dados. Os resultados: (i) mostrou informações gerais sobre o sitío e detalhou os principais setores de prestação de contas; (ii) foram divulgadas a maiorias das demonstrações requeridas pela legislação; (iii) a partir do que foi apontado anteriormente, apresentam-se sugestões de melhorias. Assim conclui-se que a UDESC cumpriu os requisitos de transparência postos pela legislação, porém deve voltar esforços ao atendimento das demais exigências, como apresentação de notas explicativas nas demonstrações financeiras.

Palavras-chave: UDESC. Transparência governamental. Internet. Contas públicas.

\begin{abstract}
The transparency of actions and accountabilities of publics spending are issues of great relevance social relevance and their absences are recurrent in discussions about the shortcomings of public administration and are agents of democracy, efficiency and change. The aim of this paper is to demonstrate the advertising practices of Internet UDESC and evaluates them in relation to legislation. This research is a descriptive qualitative approach by means of desk research, from data coming from secondary site UDESC. Checklist was used for data collection. The results: (i) shows general information on the site and details the main areas of accountability; (ii) the majority were released statements required by law; (iii) from what was previously mentioned, suggestions for improvements are presented. Thus it is concluded that UDESC fulfills the transparency requirements posed by legislation, but efforts should be made to meet the other requirements such as submission of exploratory notes of financial statements.
\end{abstract}

Keywords: UDESC. Government transparency. Internet. Public accounts. 


\section{INTRODUÇÃO}

A transparência dos atos de gestão e a prestação de contas dos gastos públicos são temas de grande relevância social e suas ausências são recorrentes nas discussões sobre as falhas da administração pública. Isso é reforçado por Cruz, Santos e Silva (2009, p. 103) que afirmam que "a transparência na gestão pública ainda encontra-se em um estágio incipiente, em decorrência da divulgação de tais informações se darem num ambiente político e cultural marcado por ideologia e interesses diversos"

A transparência e as prestações de contas dos gastos públicos constituem requisitos indispensáveis para a realização do exercício social, pois permite aproximar governo e sociedade e atua como agente da democracia, da eficiência e da mudança.

A transparência governamental é um princípio estabelecido na Constituição Federal de 1988 e reforçado na Lei de Responsabilidade Fiscal (LRF) n. 101/2000. Esse princípio obriga que as informações do setor público sejam fornecidas à sociedade, assegurando que todos tenham direito de pedir e recebê-las. Nos últimos tempos, a Internet está sendo uma das grandes ferramentas de divulgação dessas prestações de contas, dado à facilidade de acesso e abrangência. Cruz e Platt Neto (2009, p, 112) mostram que a obrigatoriedade dessa divulgação de informações na Internet surgiu com a Lei n. 9755/98. Esta Lei determinou a criação da página Contas Públicas (www.contaspublicas.gov.br), onde as entidades gestoras de recursos públicos devem divulgar informações orçamentárias e financeiras mensalmente.

As universidades públicas são entidades da Administração Pública Indireta, geralmente autarquias ou fundações, e são dependentes de recursos públicos. Por causa disso, elas são obrigadas pela Constituição Federal, a prestar contas do uso de seus recursos, e respeitar os princípios da administração pública, principalmente o da publicidade. Porém percebe-se uma relativa falta de publicidade na divulgação da prestação de contas na internet. Um exemplo disto é uma pesquisa realizada no site Contas Publicas (2011) onde se observou que embora as universidades públicas estivessem cadastradas, porém não existiam informações sobre as Contas Públicas dessas organizações.

Baseado no que foi exposto realiza-se a seguinte pergunta: Como as universidades públicas estão utilizando a Internet para suas prestações de contas, levando em conta os princípios da transparência e publicidade?

$\mathrm{Na}$ busca de resposta à pergunta da pesquisa definiu-se que o objetivo geral deste trabalho consiste analisar em o uso da Internet como instrumento de publicidade e como 
aliado na transparência das contas públicas da Universidade do Estado de Santa Catarina (UDESC). A UDESC é uma universidade pública e serão observadas as práticas com relação às suas contas no ano de 2011.

Para se atingir o objetivo principal foram identificados como objetivos específicos: (i) Demonstrar as práticas de publicidade da UDESC na Internet; (ii) Identificar a conformidade das práticas adotadas com a legislação; (iii) Oferecer sugestões de melhorias de práticas.

Este estudo é relevante no quesito originalidade, porque nos artigos selecionados para revisão de literatura não há registro sobre as práticas de publicidade de Universidades Públicas Estaduais. Há uma lacuna no conhecimento sobre as práticas de transparência e prestação de contas das Universidades Estaduais e Municipais. A importância da pesquisa é de cunho social, visto que o princípio da transparência deve ser aplicado em todos os níveis da administração pública, tendo em vista o controle social dos gastos públicos.O presente trabalho é viável, uma vez que há disponibilidade de tempo, de bibliografia necessária e acesso a dados. A partir do tempo disponível foi possível realizar todos os objetivos específicos. Foram encontrados artigos relativamente recentes, para criação do embasamento teórico necessário para esse trabalho, e a coleta de dados foi realizada a partir de dados públicos, disponibilizados na Internet.

A pesquisa restringe-se ao ano de 2011, especificamente no mês de novembro, pesquisando na site da UDESC, com foco nos setores responsáveis por fornecer as informações relevantes para prestação de contas.

\section{REFERENCIAL TEÓRICO}

\subsection{Princípio da transparência e princípio da publicidade}

O Princípio da Publicidade é definido na revisão de literatura pelo artigo 37 da Constituição Federal de 1988, como obrigatoriedade de publicidade dos atos, programas, serviços e campanhas do serviço público, devendo ter caráter educativo, informativo ou de orientação social e não pode haver promoção pessoal da autoridade ou servidores públicos. Pinho e Sacramento (2007); Ensslin et al (2008) e Cruz e Ferreira (2008) afirmam que o Princípio da Publicidade não pode ser confundido com o princípio da transparência, pois a transparência inclui o princípio da publicidade. Na Transparência além da divulgação das informações, deve existir um nível de evidenciação tal que permita à sociedade julgar as ações dos seus gestores. Amaro et al (2008, p. 2) escrevem que "a falta de transparência facilita a 
corrupção, tendo como conseqüência a falta de depósito de credibilidade da sociedade no seus governantes e o afastamento da política".

A Lei de Responsabilidade Fiscal ou Lei Complementar 101/2000 reforçou o Princípio da Transparência, corroborado por Cruz, Platt Neto e Vieira (2006, p. 137), pois afirma que a responsabilidade na gestão fiscal "pressupõe uma ação planejada e transparente e porque também apresenta os instrumentos da transparência da gestão fiscal'". Cruz da et al (2010, p. 4) e Cruz., Santos e Silva (2009, p. 104) afirmam "que a esses instrumentos deve ser dada ampla divulgação em todos os meios de comunicação, inclusive em meios eletrônicos de acesso público, como Internet”. No art. 48 são especificados esses instrumentos: os planos, orçamentos, e leis de diretrizes orçamentárias; as prestações de contas e o respectivo parecer prévio; o Relatório Resumido de Execução Orçamentária e o Relatório de Gestão Fiscal, e as versões simplificadas desses documentos.

O conceito de Princípio da Transparência utilizada por Cruz et al (2001, p. 283) é que "as informações sobre as atividades dos gestores públicos devem ser franqueadas ao público em geral, com ampla divulgação nos meios de comunicação, de forma que o público possa compreender e consequentemente participar na fiscalização dos gestores”.

Contas públicas definidas por Cruz et al (2007, p. 80) como "conjunto de dados e informações de natureza econômico-financeira das entidades públicas, produzidos pelos órgãos de contabilidade, planejamento e orçamento". Tais informações podem associar dados monetários e não-monetários, de natureza financeira, orçamentária, e operacional, das atividades organizacionais. A prestação de contas é o processo que num prazo determinado, os responsáveis pelas contas públicas devem comprovar perante o órgão competente, o uso, o emprego ou a movimentação dos bens, numerários e valores que lhe foram adjudicados ou confiados.

\subsection{Divulgação das informações das contas públicas}

A divulgação das informações é um atributo necessário para a transparência governamental, permitindo o aprimoramento das instituições, no que se refere ao desempenho dos programas de governo, transparência e responsabilidade perante a sociedade. E a partir disso permitir que a sociedade intervenha em casos de ineficiência e abusos. Existem diversos meios de comunicação usados para publicação das informações públicas como: meios impressos, a Internet, meios presenciais, televisão, rádio e meios inovadores como painéis eletrônicos e cartilhas de cidadania nas escolas. Pires, Souza e Tibeli (2010, p.4) comentam 
que a divulgação das informações referentes à gestão sejam feitas na web: pode-se falar em transparência via web.

Agostineto e Raupp (2010a, p. 6, 2010b, p. 70) afirmam que o "uso da Internet tem diversos benefícios como criação rápida e barata, aumento na qualidade dos serviços realizados e promoção de maior participação da população". Apontam-se como desvantagens: Baixa porcentagem da população tem acesso a esse meio de comunicação e não pode por si só, acabar com o déficit democrático. Cruz e Platt Neto (2009) afirmam que a obrigatoriedade de divulgar informações na Internet surgiu com Lei n 9.755/98, que criou a página da Internet (home page) Contas Públicas. Essa lei requer a divulgação de diversas informações como os relatórios da execução orçamentária, que devem estar disponíveis até sessenta dias após o encerramento do semestre. Orçamentos do exercício devem aparecer na home page até 31 de maio, sendo que os balanços do exercício anterior devem ser publicados em 31 de julho de cada ano. Alguns outros exemplos de relatórios que podem aparecer: PPA, LDO, LOA, prestações de contas, pagamentos de fornecedores, etc.

Os Indicadores que podem ser utilizados para avaliar a transparência das informações publicadas via internet são: existência ou não de site, portal ou home page; verificação de conteúdos financeiros e avaliação da facilidade de navegação e da qualidade do conteúdo.

\subsection{Estudos similares}

Na revisão da literatura buscou-se verificar o que estava sendo discutido sobre o tema no meio acadêmico. Foram destacados três artigos que possuem mais similaridades, sendo apresentados no Quadro 1 a seguir.

Nos estudos citados no Quadro 1 foi analisada a transparência governamental nas prestações de contas no setor público. No primeiro e segundo artigos foi feito um estudo de caso na Universidade Federal de Santa Catarina, que pode ser aplicado em outras universidades públicas federais. No terceiro artigo aplicou-se o estudo de caso às Câmaras Municipais da Grande Florianópolis.

\begin{tabular}{|c|l|}
\hline REFERÊNCIA & \multicolumn{1}{c|}{ FOCO DO ESTUDO } \\
\hline \multirow{3}{*}{ Cruz, Platt Neto e Vieira (2006) } & $\begin{array}{l}\text { Abordaram a transparência das contas públicas } \\
\text { nas universidades públicas federais e aplicação da } \\
\text { Internet como instrumento de transparência. A }\end{array}$ \\
$\begin{array}{l}\text { UFSC foi observada nas suas práticas adotadas, } \\
\text { no período de outubro de 2004. Nos resultados } \\
\text { foram apresentados as unidades da UFSC que são }\end{array}$ \\
\hline
\end{tabular}




\begin{tabular}{|l|l|}
\hline & $\begin{array}{l}\text { responsáveis por fornecer a prestação de contas } \\
\text { na Internet. Posteriormente houve a identificação } \\
\text { dos limites, qualidades dessas prestações e } \\
\text { também foram oferecidas sugestões. }\end{array}$ \\
\hline Cruz e Platt Neto (2009) & $\begin{array}{l}\text { Analisaram informações fornecidas pela UFSC na } \\
\text { Internet, e a partir delas construíram um painel de } \\
\text { informações institucionais básicas de uma } \\
\text { universidade pública federal. Os resultados } \\
\text { demonstraram as unidades de fornecimento de } \\
\text { informações da UFSC na Internet e o painel de } \\
\text { informações com seu detalhamento e limitações. }\end{array}$ \\
\hline Agostinetto e Raupp (2010) & $\begin{array}{l}\text { Identificam nos relatórios publicados pelas } \\
\text { Câmaras Municipais da Grande Florianópolis, nos } \\
\text { portais eletrônicos, que possam indicar prestações } \\
\text { de contas dos gastos ocorridos. Após a } \\
\text { observação dos portais eletrônicos foram } \\
\text { enviados questionários por e-mail aos Presidentes } \\
\text { das Câmaras Municipais, para que fossem } \\
\text { avaliados o processo de prestações de contas nos } \\
\text { portais. Nos resultados foram analisados os } \\
\text { portais eletrônicos e os questionários recebidos. }\end{array}$ \\
\hline
\end{tabular}

QUADRO 1 Estudos similares

Fonte: Elaborado pelo autor

O presente estudo se difere, no estudo de caso, escolhendo-se como base a Universidade do Estado de Santa Catarina, uma universidade pública estadual. Percebe-se que na literatura acadêmica não existe referência às universidades estaduais.

\section{METODOLOGIA DE PESQUISA}

Nesta seção, apresenta-se a metodologia da pesquisa, onde se aborda: (i) o enquadramento metodológico, (ii) procedimentos para revisão da literatura; e, (iii) procedimentos para coleta e análise dos dados.

\subsection{Enquadramento metodológico}

A pesquisa apresentada tem caráter descritivo (GIL, 2007), pois serão analisadas e descritas as práticas utilizadas na prestação de contas da UDESC (http://www.udesc.br/) na Internet, no período de outubro e novembro de 2011.

A lógica dessa pesquisa é dedutiva (RICHARDSON, 1999), porque se conhece o que a legislação exige com relação às prestações de contas e a partir desse conhecimento será verificado se a UDESC está cumprido os requisitos impostos pela legislação. 
O procedimento técnico adotado é a pesquisa documental (RICHARDSON, 1999), porque a presente pesquisa foi elaborada a partir das informações oferecidas pelo site da UDESC, com foco nos setores responsáveis por fornecer as informações relevantes para prestação de contas. Ao mesmo tempo na coleta de dados serão utilizados dados secundários (RICHARDSON, 1999), que serão obtidos de relatórios. Os dados coletados serão analisados e com base neles será possível verificar as práticas correntes adotadas.

A abordagem do problema é qualitativa (RICHARDSON, 1999), pois existe a necessidade de identificar as práticas de prestação de contas de acordo com os dados pesquisados. Isto será reforçado pelos objetivos específicos que são a demonstração das práticas da UDESC na Internet, identificação das qualidades e defeitos dessas práticas e uma contribuição de sugestões de melhorias.

\subsection{Procedimentos para coleta e análise dos dados}

No estudo foram coletados dados que são de fontes secundárias, compostas pela legislação que regula a prestação de contas na Internet e o próprio site da UDESC. O período da coleta de dados foi o ano de 2011 no mês de novembro.

O primeiro objetivo específico é demonstrar as práticas de publicidade na Internet da UDESC. Para atingí-lo, será analisado o sítio da UDESC, com foco nos setores responsáveis por informações relevantes para prestação de contas. Essas informações são os balanços públicos, pagamentos de fornecedores, demonstrativo de orçamento, proposta orçamentária, execução orçamentária, distribuição por unidade orçamentária, relatório de gestão, Relatório de Auditoria da Controladoria Geral da União (CGU) e as determinações do Tribunal de Contas da União (TCU). Será utilizado um método semelhante ao proposto por Cruz e Platt Neto (2009) e Agostineto e Raupp (2009). Nessa busca no site será verificado inicialmente a existência ou não do site. Em seguida, se estão disponíveis as demonstrações financeiras, do período e de períodos anteriores, se possui ou não sistema de busca por palavras para facilitar a busca, sua funcionalidade, e se há possibilidade de downloads.

Para atingir o segundo objetivo será verificado, se as práticas de publicidade da UDESC na Internet estão de acordo com a legislação que trata do assunto. Serão demonstrados os relatórios exigidos pela legislação, com sua disponibilidade e as notas explicativas.

O terceiro objetivo específico consiste em relacionar os pontos onde as práticas de publicidade podem ser melhoradas. Serão relacionadas sugestões de atitudes e procedimentos 
que podem ser adotados como instrumento de sanar as deficiências constatadas na consecução dos objetivos 1 e 2 . Ou seja, a partir do que foi apontado nas etapas anteriores, serão sugeridas soluções. Por exemplo: O sistema de busca do sítio não funciona para algumas palavras relevantes para a prestação de contas como "balanço", "orçamento", "gestão". A solução seria que o sistema fosse ajustado para fornecer resultados relacionados a essas palavras, já que existe no sítio um setor "Transparência", que possui esses dados.

\subsection{Procedimentos para seleção do referencial teórico}

Para composição do referencial teórico, fez-se a busca de artigos relacionados ao tema, nos 13 periódicos vinculados aos Programas de Pós-Graduação em Ciências Contábeis em nível de Mestrado e Doutorado, recomendados pela Capes, a saber: Brazilian Business Review; Revista de Administração e Contabilidade da Unisinos; Revista Contabilidade e Organizações; Revista de Contabilidade do Mestrado em Ciências Contábeis; Revista Universo Contábil; Contabilidade de Vista \& Revista; Contabilidade e Finanças; Revista Brasileira de Gestão e Negócios; Revista da Informação Contábil; Revista de Contabilidade da UFBA; Revista Contabilidade \& Controladoria; Revista Contemporânea de Contabilidade e Contabilidade, Gestão e Governança. Utilizou-se esses periódicos na formação da base teórica por concentrarem publicações de artigos relevantes para o presente estudo. Também foram selecionados os seguintes eventos: o Congresso USP de Controladoria e Contabilidade e o Encontro Anual da Associação Nacional dos Programas de Pós-Graduação (EnANPAD).

A pesquisa dos artigos selecionados foi realizada a partir do site dos periódicos e nos anais dos eventos disponíveis em meio eletrônico. O período de busca foi de 2006 a 2010 . As três palavras chaves utilizadas foram: Transparência Governamental, Publicidade na Administração Pública e Divulgação de Prestações de Contas.Foram encontrados 15 artigos no total: 12 em periódicos e 3 em congressos. Destes foram selecionados 12 artigos, que pela leitura integral constatou-se estarem alinhados ao tema deste trabalho. Esses artigos serão utilizados para o embasamento teórico desta pesquisa.

Os artigos utilizados são:

1. Transparência orçamentária municipal via web (TOM Web) após a Lei Complementar 131/09: os casos da Região Administrativa Central do Estado de São Paulo - 2010

2. Um Estudo Empírico sobre a Transparência da Gestão Pública dos Grandes Municípios Brasileiros 
3. Transparência das Contas Públicas: Um enfoque no uso da Internet como instrumento de publicidade na UFSC

4. Proposta de um Painel de Informações Sintéticas sobre as Universidades: Aplicação do "Raio-X " na Universidade Federal de Santa Catarina

5. Proposta de um Modelo para Avaliar o Grau de Transparência das Demonstrações Financeiras Publicadas por uma Instituição Pública de Ensino Superior Brasileira: A abordagem da Metodologia Multicritério de Apoio à Decisão Construtivista

6. Transparência da gestão fiscal: um estudo a partir dos portais eletrônicos dos maiores municípios do Estado do Rio de Janeiro

7. Transparência na elaboração, execução e prestação de contas do orçamento municipal: um estudo em um município brasileiro

8. Uma discussão sobre a criação de indicadores de transparência na gestão pública federal como suporte ao ciclo da política pública

9. Transparência na Administração Pública: O que mudou depois da Lei de Responsabilidade Fiscal? Um estudo exploratório em seis municípios da região metropolitana de Salvador

10. Publicidade e Transparência das Contas Públicas: Obrigatoriedade e abrangência desses princípios na administração pública brasileira

11. Prestação de contas por meio de portais eletrônicos: Um estudo em Câmaras Municipais da Grande Florianópolis

12. Investigando a Prestações de Contas em Portais Eletrônicos de Câmaras Municipais

$\mathrm{Na}$ leitura dos artigos constatou-se que a maioria deles citam a Constituição Federal e a Lei de Responsabilidade Fiscal. Sendo assim, decidiu-se incluir no referencial teórico essas duas Leis.

\section{RESULTADOS}

Nesta seção são apresentadas as práticas de publicidade das contas públicas da Universidade do Estado de Santa Catarina (UDESC). Inicialmente são apresentadas as informações gerais sobre o sítio e logo em seguida os setores responsáveis pela divulgação das informações sobre as contas públicas. Posteriormente é verificado se a legislação está sendo cumprida em relação a essas práticas de publicidade. E a partir das informações demonstradas nas etapas anteriores, são apresentadas sugestões de melhorias.

A UDESC foi criada em 20 de maio de 1965, pelo Decreto 2.802, mas foi instituída como Fundação pela Lei no 8092 de $1^{\text {o }}$ de outubro de 1990. Tem sua Reitoria sediada em Florianópolis, integra o Sistema Estadual de Educação do Estado de Santa Catarina e goza de autonomia didático-científico, administrativa e de gestão financeira, disciplinar e patrimonial.

Tem como missão a produção, sistematização, socialização e aplicação do conhecimento nos diversos campos do saber, para contribuir para uma sociedade mais justa e 
democrática em prol da qualidade de vida e desenvolvimento sustentável do Estado de Santa Catarina (UDESC, 2011).

Foi realizada análise do site no mês de novembro de 2011, onde observou-se aspectos gerais sobre o sítio eletrônico, conforme apresentado no Quadro 2.

\begin{tabular}{|l|c|}
\hline \multicolumn{1}{|c|}{ INFORMAÇÕES SOBRE O SíTIO } & POSSUI? \\
\hline Existência ou não de sítio & ( X ) Sim ( ) Não \\
\hline Demonstrações financeiras divulgadas no prazo & ( X ) Sim ( ) Não \\
\hline Possui sistema que facilite a busca & ( X ) Sim ( ) Não \\
\hline Sistema de busca funciona corretamente? & ( ) Sim ( X ) Não \\
\hline $\begin{array}{l}\text { Mantêm disponíveis as Demonstrações } \\
\text { financeiras dos anos anteriores }\end{array}$ & ( ) Sim ( X) Não \\
\hline É possível fazer download da documentação ? & ( X ) Sim ( ) Não \\
\hline
\end{tabular}

QUADRO 2 Informações gerais sobre o sítio

Fonte: Dados da pesquisa

Numa verificação geral, as demonstrações financeiras mais recentes, que são de 2010, estão disponíveis no site, por outro lado não existe demonstrações anteriores ao ano de 2010 , o mais recente, o que dificulta fazer comparações com os anos anteriores, pois não se tem uma base de que possibilite uma comparação com as demonstrações atuais. Uma comparação com resultados de Cruz, Orion e Vieira (2006) que analisaram o sítio eletrônico da Universidade Federal de Santa Catarina (UFSC), e apontaram que a UFSC possuía os balanços orçamentário, financeiro, patrimonial e variações financeiras dos anos 1999 a 2001, ou seja, possuía as demonstrações anteriores, mas não as mais atuais.

Existe um sistema de busca no sítio, porém as palavras relevantes para esse estudo que quando são pesquisadas, são substituídos pela palavra padrão "pesquisar", o que dificulta o processo de análise. Isso é amenizado pelo "Indice A-Z", que lista as diversas sessões do site.

As demonstrações e relatórios estão em formato Adobe Acrobat $(p d f)$ o que torna eficiente para download e impressão. Isso é comparado com as observações de Cruz, Orion e Vieira (2006) que a UFSC utiliza o formato $\mathrm{html}$ o que dificulta a impressão e a transposição dos demonstrativos para editores de textos e planilhas eletrônicas, entretanto, facilita a navegação.

Serão detalhados no Quadro 3 a seguir alguns setores da UDESC que possuem informações relevantes para a pesquisa:

A Coordenaria de Documentação pelo que consta no sítio tem como objetivo controlar as política arquivísticas, os procedimentos internos e externos em relação à comunicação e a 
incorporação e utilização das tecnologias de informação e comunicação. São disponibilizados nesse setor os instrumentos de gestão.

\begin{tabular}{|l|l|l|l|}
\hline \multicolumn{1}{|c|}{ Setor } & \multicolumn{1}{|c|}{ Função } & \multicolumn{1}{c|}{ Homepage } & Informações encontradas \\
\hline $\begin{array}{l}\text { Coordenadoria de } \\
\text { Documentação }\end{array}$ & $\begin{array}{l}\text { Controle das políticas e } \\
\text { procedimentos em } \\
\text { relação aos documentos }\end{array}$ & http://www.udesc.br/?id=220 & Instrumentos de Gestão \\
\hline Institucional & $\begin{array}{l}\text { Fornecer as informações } \\
\text { básicas sobre a entidade }\end{array}$ & $\mathrm{http} / / /$ www.udesc.br/?id=425 & $\begin{array}{l}\text { Plano 20, Relatório de } \\
\text { Gestão e Balanço Social }\end{array}$ \\
\hline $\begin{array}{l}\text { Pró-Reitoria de } \\
\text { Planejamento }\end{array}$ & $\begin{array}{l}\text { Coordena, orienta e } \\
\text { supervisiona as } \\
\text { atividades de } \\
\text { planejamento }\end{array}$ & http://www.udesc.br/?id=64 & $\begin{array}{l}\text { Convênios, Orçamento e } \\
\text { Atos de Pessoal }\end{array}$ \\
\hline $\begin{array}{l}\text { Transparência } \\
\text { UDESC }\end{array}$ & $\begin{array}{l}\text { Consolidação dos } \\
\text { documentos necessários } \\
\text { para transparência }\end{array}$ & http://www.udesc.br/?id=787 & $\begin{array}{l}\text { Balanço Social, } \\
\text { Demonstrativos Contábeis, } \\
\text { Orçamento, Atos de } \\
\text { Pessoal, Relatório de } \\
\text { Gestão e Convênios }\end{array}$ \\
\hline
\end{tabular}

QUADRO 3 Informações sobre os setores da UDESC que disponibilizaram informações sobre a prestação de contas

Fonte: Dados de pesquisa

O setor Institucional da página da UDESC é onde contêm as informações básicas da entidade como objetivos, finalidades, princípios, a missão e a estrutura organizacional. Esse setor possui o Relatório de Gestão de 2004 até 2010, o Plano 20, que é planejamento da UDESC de 20 em 20 anos, começando por 2005-2025, indo 2007-2027 e chegando no 20102030, e o Balanço Social.

A Pró-Reitoira de Planejamento pelo que consta no sítio "é o órgão executivo, que orienta, coordena e supervisiona as atividades de planejamento da UDESC" Algumas das atribuições são coordenar a Elaboração do Plano Geral e de Metas, do Planejamento anual e plurianual e elaboração do orçamento. São disponibilizados os convênios, contratos e o Orçamento, sendo dentro desse último a Plano Plurianual (PPA), Lei de Diretrizes Orçamentária (LDO), Lei Orçamentária Anual(LOA), Quadro de Detalhamento de Despesas (QDD), quadro síntese por fontes e grupos de despesas, detalhamento de crédito orçamentário e distribuição orçamentária UDESC. Estão abrangidas no Orçamento de 2009 até 2011.

No setor Transparência UDESC são consolidados os diversos documentos relacionados com a publicidade. Isso representa uma salutar iniciativa da UDESC, pois consolidando-os em só uma seção reduz-se o trabalho de procura e permite maior conveniência. Em geral, uma prática que poderia ser adotada por outros websites. Pode ser 
encontrado os registros contábeis, Balanço Social, Demonstrativos Contábeis (financeiro, orçamentário, patrimonial e variações patrimoniais), Orçamento, Atos de Pessoal, Relatório de Gestão e Convênios.

Em comparação aos resultados desta pesquisa com a de Cruz e Platt Neto (2009), pode se perceber que a UFSC têm sua prática de publicidade mais pulverizadas pelo sitío eletrônico, enquanto a UDESC concentrou mais na Pró-Reitoria de Planejamento e a Transparência UDESC.

A seguir será verificado se as práticas de publicidade da UDESC na Internet estão de acordo com a legislação vigente. Quando a localização dos relatórios exigidos pela legislação e a disponibilização de notas explicativas, foi observado o que apresenta-se no Quadro 4.

\begin{tabular}{|c|c|c|}
\hline $\begin{array}{l}\text { RELATÓRIOS EXIGIDOS } \\
\text { PELA LEGISLAÇÃO }\end{array}$ & ESTÃO DISPONÍVEIS? & NOTAS EXPLICATIVAS \\
\hline Balanço orçamentário & (X) Sim ( ) Não & ( ) $\operatorname{Sim}(X)$ Não \\
\hline Balanço financeiro & (X) $\operatorname{Sim}($ ) Não & ( X) Sim ( ) Não \\
\hline Balanço patrimonial & (X) $\operatorname{Sim}($ ) Não & ( ) $\operatorname{Sim}(X)$ Não \\
\hline $\begin{array}{l}\text { Balanço de variações } \\
\text { patrimoniais }\end{array}$ & ( X) Sim ( ) Não & ( ) $\operatorname{Sim}(X)$ Não \\
\hline Pagamentos de fornecedores & (X) $\operatorname{Sim}($ ) Não & ( ) $\operatorname{Sim}(X)$ Não \\
\hline Demonstrativo de orçamento & (X) $\operatorname{Sim}($ ) Não & ( ) $\operatorname{Sim}(X)$ Não \\
\hline Proposta orçamentária & (X) $\operatorname{Sim}($ ) Não & ( ) $\operatorname{Sim}(X)$ Não \\
\hline $\begin{array}{l}\text { Relatório Resumido de } \\
\text { Execução Orçamentária }\end{array}$ & (X) $\operatorname{Sim}($ ) Não & ( ) $\operatorname{Sim}(X)$ Não \\
\hline $\begin{array}{l}\text { Distribuição por unidade } \\
\text { orçamentária }\end{array}$ & (X ) $\operatorname{Sim}($ ) Não & ( ) $\operatorname{Sim}(X)$ Não \\
\hline Relatório de Gestão Fiscal & (X) $\operatorname{Sim}($ ) Não & ( ) $\operatorname{Sim}(X)$ Não \\
\hline $\begin{array}{l}\text { Relatório de Auditoria da } \\
\text { Controladoria Geral da União }\end{array}$ & ( ) $\operatorname{Sim}(X)$ Não & ( ) $\operatorname{Sim}(X)$ Não \\
\hline $\begin{array}{l}\text { Determinações do Tribunal } \\
\text { de Contas da União }\end{array}$ & ( ) $\operatorname{Sim}(X)$ Não & ( ) $\operatorname{Sim}(X)$ Não \\
\hline Relatório da Auditoria Interna & ( ) $\operatorname{Sim}(X)$ Não & ( ) $\operatorname{Sim}(X)$ Não \\
\hline Plano Plurianual & (X) Sim ( ) Não & ( ) Sim (X) Não \\
\hline $\begin{array}{l}\text { Lei de Diretrizes } \\
\text { Orçamentárias }\end{array}$ & (X) Sim ( ) Não & ( ) $\operatorname{Sim}(X)$ Não \\
\hline Lei Orçamentária Anual & (X) Sim ( ) Não & ( ) $\operatorname{Sim}(X)$ Não \\
\hline $\begin{array}{l}\text { Parecer Prévio da Prestação } \\
\text { de Contas }\end{array}$ & ( ) $\operatorname{Sim}(X)$ Não & ( ) $\operatorname{Sim}(X)$ Não \\
\hline $\begin{array}{l}\text { Lei de Diretrizes } \\
\text { Orçamentárias Simplificada }\end{array}$ & ( ) $\operatorname{Sim}(X)$ Não & ( ) $\operatorname{Sim}(X)$ Não \\
\hline Plano Plurianual Simplificada & ( ) $\operatorname{Sim}(X)$ Não & ( ) $\operatorname{Sim}(X)$ Não \\
\hline $\begin{array}{l}\text { Relatório de Gestão Fiscal } \\
\text { Simplificado }\end{array}$ & ( ) $\operatorname{Sim}(X)$ Não & ( ) $\operatorname{Sim}(X)$ ) Não \\
\hline $\begin{array}{l}\text { Lei Orçamentária Anual } \\
\text { Simplificada }\end{array}$ & ( ) $\operatorname{Sim}(X)$ Não & ( ) $\operatorname{Sim}(X)$ Não \\
\hline
\end{tabular}


Relatório Resumido de Execução Orçamentária Simplificado
( ) $\operatorname{Sim}(X)$ Não

( ) Sim (X ) Não

QUADRO 4 Cumprimento ou na da legislação

Fonte: Dados de pesquisa

Pode-se perceber que a maioria $(80 \%)$ das demonstrações não possuem nota explicativas, o que dificulta a compreensão das demonstrações apresentadas, principalmente em balanços, pois é olhando apenas para números é complicado entender como chegou aos resultados, apenas pela visualização dos números. Isso é reforçado por Cruz, Platt Neto e Vieira (2006) que constataram que a falta de notas explicativas é uma ocorrência comum no âmbito da administração pública. Esta apresenta-se como uma prática que necessita de melhoria por parte da instituição para cumprir seu papel de dar transparência aos autos de gestão.

O sítio possui uma sessão destinada à Secretaria de Controle Interno (SECONTI), porém não foi encontrando o Relatório de Auditoria da Controladoria Geral da União, Determinações do Tribunal de Contas da União e o Relatório da Auditoria Interna. A falta desses relatórios dificulta uma avaliação nas mudanças pedidas por esses relatórios. Comparam-se com os resultados de Cruz e Platt Neto (2009), que na Auditoria Interna da UFSC é demonstrado esses relatórios, junto com as ações adotadas para correção dessas impropriedades.

Na sessão Orçamento (http://www.udesc.br/?id=214) foi possível encontrar vários dos documentos relativos, porém não continha as versões simplificadas delas e que deveriam aparecer por causa do art. 48 da LRF.

\subsection{Sugestões de melhoria}

A partir do que foi exposto nas seções anteriores será apresentado algumas sugestões de melhorias. O sistema de busca poderia ser aprimorado pela inclusão algumas palavraschave como auditoria, balanços, e corrigir uma falha quando se aperta o botão da lupa, que transforma a palavra que está no sistema de busca em "pesquisar".

Nos balanços patrimoniais, financeiros, orçamentárias e de variações patrimoniais poderiam ser apresentados os valores dos exercícios anteriores, por exemplo, o balanço orçamentário de 2010, poderia ter mais duas colunas, a de 2008 e 2009, o que tornaria mais fácil conferir as mudanças que ocorreram. Poderia adicionar também para o financeiro, patrimonial e de variações patrimoniais as notas explicativas. 
Adição das versões simplificadas da LDO, PPA, LOA, Relatório de Gestão Fiscal e Relatório Resumido de Execução Orçamentária Simplificado. E na SECONTI poderia ser adicionado Relatório de Auditoria da Controladoria Geral da União, Determinações do Tribunal de Contas da União e o Relatório da Auditoria Interna.

\section{CONSIDERAÇÕES FINAIS}

A transparência é um tema de relevância social, necessária para aplicação do controle social por parte da sociedade e permitindo uma melhora na eficiência. A Internet serve como um grande instrumento de divulgação de dados, oferecendo benefícios como criação rápida e barata.

Considera-se que foi atingido o objetivo geral, de analisar o uso da Internet como instrumento de publicidade e como aliado na transparência das contas públicas da UDESC. Os objetivos específicos também foram atingidos, o primeiro a demonstração das práticas de publicidade, sendo o segundo objetivo, a verificação da conformidade dessas práticas pela legislação e o último objetivo à apresentação de sugestões de melhorias para o sítio eletrônico.

Pelo referencial teórico foi possível entender melhor o Princípio da Transparência e o Princípio da Publicidade, junto com a legislação relacionada com Constituição de 1984 e a LRF. Com essas informações, foi possível sustentar a exigência de prestação pública e de suas informações fornecidas para população. Também no referencial teórico foi comentado sobre a divulgação das contas públicas, os seus motivos de ser, os meios utilizados, principalmente a Internet.

No capítulo de resultados foram demonstrados inicialmente os resultados do primeiro objetivo específico, de apresentar as práticas de publicidade da UDESC na Internet, contendo nos Quadros 2 e 3 as informações gerais sobre o sítio eletrônico da UDESC e alguns setores da UDESC relacionados com a publicidade e o comprimento com a legislação. Logo em seguida no segundo objetivo especifico de identificar a conformidade das práticas adotadas com a legislação, foi apresentado no Quadro 4 os documentos requeridos pela legislação, com a existência deles ou não no sítio eletrônico e se as demonstrações contábeis possuem notas explicativas. O último objetivo foi de fornecer sugestões de melhorias a partir do que foi apontado nos dois objetivos anteriores, sendo que os resultados se encontram na seção 4.1. . A partir do que foi exposto conclui-se que a publicidade da UDESC é relativamente boa, com algumas boas idéias como consolidação em único setor dos documentos relacionados a transparência, mas como foi apontado na sessão sugestões, existe possibilidade de melhoras. 
As limitações desse estudo ocorrem pelo foco no estudo de caso de uma única universidade estadual, o que não pode refletir as outras universidades estaduais, que possuem as suas próprias peculiaridades. Assim para futuras pesquisas poderia ser aplicado o procedimento de coleta e análise de dados em outras universidades estaduais, para futura comparação.

\section{REFERÊNCIAS}

AGOSTINETO, Raquel Crestani; RAUPP, Fabiano Maury. Prestação de Contas por meio de portais eletrônicos: um estudo em Câmaras Municipais da Grande Florianópolis. Revista Universo Contábil, Blumenau, v. 5, nº 3, p 64-79, jun./set. , $2010 \mathrm{a}$.

. Investigando a Prestação de Contas em Portais Eletrônicos de Câmera Municipais. In: CONGRESSO USP, 2010, São Paulo Anais Eletrônicos. São Paulo, 2010 b.

AMARO, Rodrigo Gayser et al. Uma discussão sobre a criação de indicadores de transparência na gestão pública federal como suporte ao ciclo da política pública. Revista de Contabilidade do Mestrado em Ciências Contábeis da UERJ, v. 13, n², p 15-29, maio/ago. , 2008.

BRASIL. Constituição (1988). Constituição da República Federativa do Brasil, promulgada em 5 de outubro de 1988.

Lei $n^{\circ} 9.755$, de 16 de dezembro de 1998. Dispõe sobre a criação de "homepage" na "Internet", pelo Tribunal de Contas da União, para divulgação dos dados e informações que específica, e dá outras providências.

Lei Complementar $n^{\circ} 101$, de 4 de maio de 2011 (Lei de Responsabilidade Fiscal). Estabelece normas de finanças de finanças públicas voltadas para a responsabilidade na gestão fiscal e dá outras providências.

CRUZ, Cláudia Ferreira; SILVA, Lino Martins; SANTOS, Ruthberg. Transparência da Gestão Fiscal: um estudo a partir dos portais eletrônicos dos maiores municípios do Estado do Rio de Janeiro, Revista Contabilidade, Gestão e Governança, Brasília v. 12, nº 3, p 102-115, set./dez. 2009.

CRUZ, Cláudia Ferreira da; FERREIRA, Aracéli Cristina de Souza. Transparência na elaboração, execução e prestações de contas do orçamento municipal: um estudo em um município brasileiro. Revista de Contabilidade do Mestrado em Ciências Contábeis da UERJ, v. 13, no2, p 1-14, maio/ago, 2008.

CRUZ, Cláudia da et al. Um Estudo Empírico sobre a Transparência da Gestão Pública dos Grandes Municípios Brasileiros. In: ENCONTRO DA ASSOCIAÇÃO NACIONAL DE PÓS-GRADUAÇÃO E PESQUISA EM ADMINISTRAÇÃO, 2010, Vitória, Anais Eletrônicos. Vitória, 2010. 
CRUZ, Flávio da et al. Lei de Responsabilidade Fiscal comentada: Lei Complementar n 101, de 4 de maio de 2000. 2. ed. São Paulo: Atlas, 2001. 346p.

. Publicidade e Transparência das Contas Públicas: obrigatoriedade e abrangência desses princípios na administração pública brasileira. Contab. Vista \& Rev. v. 18, nº 1, p. 75-94, jan./fev. 2007.

CRUZ, Flávio da; PLATT NETO, Orion Augusto. Proposta de um Painel de Informações Sintéticas sobra as Universidades: Aplicação do "Raio-X" na Universidade Federal de Santa Catarina. Revista de Contemporânea de Contabilidade, Florianópolis v. 1, nº 12, p 109-126, Jul/Dez, 2009.

CRUZ, Flávio da; PLATT Neto, Orion Augusto; VIEIRA, Audi Luiz. Transparência das Contas Públicas: um enfoque no uso da internet como instrumento de publicidade na UFSC. Revista Contemporânea de Contabilidade, Florianópolis, v. 1, nº 5, p 135-146, jan./jun. , 2006.

FREY, Márcia Rosane; MARCUZZO, Juliana Luiza; OLIVEIRA, Carine de. O balanço social como ferramenta de transparência setor público municipal. Revista Universo Contábil. Blumenau, v. 4, n², p. 75-92, abr./jun. 2008.

ENSSLIN, Leonardo et al. Proposta de um Modelo para Avaliar de um Transparência das Demonstrações Financeiras Publicadas por uma Instituição Pública de Ensino Superior Brasileira: a abordagem da Metodologia Multicritério de Apoio à Decisão Construtivista. Revista Contabilidade, Gestão e Governança, Brasília, v. 11, nº 1-2, p 170-186, jan/dez 2008.

GIL, Antônio Carlos. Como elaborar projetos de pesquisa. 4ª ed. São Paulo Atlas: 2007. PINHO, José Antônio Gomes; SACRAMENTO, Ana Rita Silva. Transparência na Administração Pública: o que mudou depois da Lei de Responsabilidade Fiscal ? Um estudo exploratório em seis municípios da Região Metropolitana de Salvador. Revista de Contabilidade da UFBA, Bahia, v. $1 \mathrm{n}^{\circ}$ 1, p 48-61 set./dez. 2007.

PIRES, Valdemir; SOUZA, Mariana Carneiro de; TIBALI, Luiz Ricardo. Transparência orçamentária municipal via web (TOM web) após Lei Complementar 131/09: os casos da Região Administrativa Central do Estado de São Paulo - 2010. In: ENCONTRO DA ASSOCIAÇÃO NACIONAL DE PÓS-GRADUAÇÃO E PESQUISA EM ADMINISTRAÇÃO, 2010, Vitória, Anais Eletrônicos. Vitória, 2010.

ROGERS, Pablo; SENA, Ludiany Barbosa. Análise Agregada dos Municípios Mineiros de Grande Porte Quanto à Adequação à Lei de Responsabilidade Fiscal (LRF). . Revista Contemporânea de Contabilidade, Florianópolis, v. 1, nº 8, p 99-119, jul./dez. 2007.

RICHARDSON, Roberto Jerry. Pesquisa Social: métodos e técnicas. 3 ed. São Paulo: Atlas, 1999

TCU - Tribunal de Contas da União. Homepage Contas Públicas. Disponível em: http://www.contaspublicas.gov.br. Acesso em: 8 out. 2011. 